Semantics \& Pragmatics Volume o, Article 1: 1-15, 2007

O doi: 10.3765 sp.o.1

\title{
Semantics and Pragmatics - A New Journal*
}

\author{
David Beaver \\ Kai von Fintel \\ University of Texas at Austin Massachusetts Institute of Technology
}

Published 2007-11-27

\begin{abstract}
We introduce the principles behind the launch of a new journal in semantics and pragmatics and outline the journal's processes and policies. $S \& P$ is a peer-reviewed open access journal. The main content is high quality, original, self-contained research articles on the semantics and pragmatics of natural languages. While our target audience is primarily academic linguists, we expect to also publish material by, or of relevance to, philosophers, psychologists, and computer scientists.
\end{abstract}

Keywords: semantics, pragmatics, linguistics, journal, publishing, open access, eLanguage

\section{Ladies and gentlemen, please submit your papers!}

We are proud to announce that Semantics and Pragmatics $(S \& P)$ is now open for submissions. $S \& P$ is a peer-reviewed open access journal, located on the web at semprag.org. Its mission is to bring the very best articles in semantics, pragmatics and allied subfields, to as wide an audience as possible, at no cost to readers or authors, as quickly as possible. The journal is affiliated with, and electronically published by, the Linguistic Society of America (under the umbrella of their eLanguage initiative: lsadc.org/info/pubs-elang-rfp.cfm and elanguage.net).

* We thank Chris Potts and Chung-chieh Shan for their work on the $\mathrm{LT}_{\mathrm{E} X} \mathrm{X}$ et-up, Leslie Hastings of Kodiak Web Design for her work on the journal's website, Emilie Destruel for her administrative assistance, Cornelius Puschmann and others in Düsseldorf and Köln for their technical work on eLanguage, Dieter Stein and the rest of the eLanguage team, the Linguistic Society of America, our Advisory Board and Editorial Board members, the MIT Library, especially Ann Wolpert, Theresa Tobin, and Ellen Finnie Duranceau, the MIT Department of Linguistics and Philosophy, the MIT School of Humanities, Arts, and Social Sciences, and the University of Texas at Austin.

(C)2007 David Beaver \& Kai von Fintel

This is an open-access article distributed under the terms of a Creative Commons NonCommercial License (creativecommons.org/licenses/by-nc/3.o). 
One might ask why the field of semantics and pragmatics needs another journal, given that we are well-served by Linguistics \& Philosophy, Natural Language Semantics, Journal of Semantics, and other respected journals. Well, $S \& P$ will be a new kind of journal, leveraging the advances in desktop publishing, open source journal management software, and internet communications infrastructure. Our aim is to publish a high-quality, peer-reviewed journal on a par with the established journals but with two very significant advantages:

- fast turn-around from submission to publication, facilitated by the all-electronic journal management plus online-first publication;

- open, immediate, and free access to anyone with an internet connection.

We ask everyone in the field to spread the word about the new journal and to encourage submission of new work to $S \& P$. Submissions are accepted via the journal's site at semprag.org. There is more information on the site, and below in Section 6.

\section{What we will publish (and what authors can do about it)}

The main content of $S \& P$ will be high quality, original, self-contained research articles on the semantics and pragmatics of natural languages. While the core of our target audience is academic linguists, we expect to also publish material by, or of relevance to, philosophers, psychologists, and computer scientists.

Papers must include new results of interest to those working in semantics and pragmatics, and must demonstrate clear significance for theoretical development of those areas. Provided the work meets those criteria, we will welcome both submissions of papers on core topics in semantics and pragmatics, and submissions of interdisciplinary papers involving work on syntax, phonology, psycho-linguistics, text and corpus studies, discourse and conversation analysis, computational semantics, the lexicon, historical linguistics, cross-linguistic typology, logic, and philosophy of language.

We have an ambitious goal: to publish as many as possible of the top 100 articles in semantics and pragmatics in a given year, and no other full articles. Issues that reviewers will be directed to consider include the following: 
A New Journal

Originality Are there important new theoretical insights, important new data, perhaps a notably original synthesis of ideas from disparate fields, or new formal techniques? Does the paper substantially overlap with a separate published paper of the author?

Advice to authors: Originality is the most basic requirement for $S \& P$ articles. However, and even though we must take into account any duplication of previously available material, overlap with a prior conference paper, thesis or other work does not automatically prevent publication in $S \& P$. Each such case will be considered on its merits, subject to applicable copyright limitations. We might, for example, consider publishing material that overlaps with an existing publication if we judge that the new publication in $S \& P$ would serve the field by bringing visibility to important developments that might otherwise be overlooked.

Technical competence and presentation of technical material Are there minor or major examples of sloppiness or misunderstanding? Are there places where the argumentation should be strengthened? Would the paper be improved with new statistical analyses, proofs of claims, or worked examples demonstrating proposed techniques? Should graphs, tables, or other presentations of data be added or modified?

Advice to authors: Obviously if reviewers pick up on issues of this sort, the paper cannot be accepted without modification. Accepting subject to revision is possible, but we will only consider accepting a paper subject to revision if it is absolutely clear to us what changes are needed.

Audience Consider the background someone would need to follow the main thread of this paper, e.g. only a few specialists, most of those who give papers at major semantics conferences, most people with a few graduate level semantics courses, most people who've taken a graduate level introduction to semantics and pragmatics, or perhaps any smart educated person with access to a search engine could follow the main thread. And if this is the population that could follow the main thread, are there nonetheless parts of the paper that are much more demanding? Might minor changes substantially increase the potential audience? 
Advice to authors: There is no single audience profile for an $S \& P$ paper, though we will always discourage unnecessary complexity or use of jargon. The case is clearest at both ends: (i) if a paper has only a limited readership, it must be clear that the paper presents extraordinary results, and (ii) having a wide potential readership is neither necessary nor sufficient for acceptance.

Quality of prose Is the paper stylish, clear, and concise? Is it unclear in places, but probably repairable by the author? Could the prose be repaired by a native English speaker who has no special training in semantics and pragmatics, or would rewriting require both the author and probably also outside help of a native English speaker?

Advice to authors: We strongly recommend that all authors, whatever their native language, have their papers proofread by a native English speaker who is competent in linguistics. Reviewers provide their services for free, and we cannot expect them to wade through prose which is unclear or written in poor English. So if we, the editors, find the quality of English in a paper to be poor, we are likely not to even send the paper for review, so that we can avoid burdening our reviewers with it.

Contextualization of research Are the main research questions contextualized in terms of earlier related work? Does the paper adequately cite related work? Could the impact of the paper be improved through modifications that would show the relevance of the results to future work in the same or other fields?

Advice to authors: by contextualizing results appropriately, the author not only increases the worth of the paper to the audience, but also makes the job of the editors and reviewers easier. It will be much easier for us to be sure that a paper should be published if we can clearly see what previous work it betters. Authors would do well to flag, both in the abstract and early on in the paper, the relationship of the paper to earlier proposals, and to indicate in broad terms what the relative advantages of the new approach are. Of course, it is then incumbent on the author to make sure that all such claims are fully justified in the main text of the article.

Subject matter and methodology The range of topics on which we can accept submissions is broad, though not so broad as for a general 
A New Journal

interest journal such as Language. Further, we have no intention to delimit the possible scope of the journal, beyond saying that articles must be highly relevant to the work of specialists in the fields of semantics and pragmatics. However, we do detect some important trends in these fields both as regards subject matter, and as regards methodology, and we hope to publish work which emphasizes these trends. In particular, we note the following trends:

i. In the last decade, there has been a flowering of cross-linguistic work, much of it tackling relatively little studied languages, and often based on fieldwork. In this regard, we might say that semantics and pragmatics are finally 'catching up' with sister fields like phonology.

ii. The creation of large corpora of text and speech, together with computer search techniques, have made new sources of data available. The citation of naturally occurring web examples is now de rigeur, and we anticipate that more sophisticated statistical and quantitative analyses, analyses which take into account both the advantages and potential pitfalls of corpus and web data, will become ever more common in the field.

iii. There is a small but growing tendency for work in the area to include or reference experimental data, sometimes involving evidence from acquisition. This development is of particular importance for pragmatics, an area where judgments based on data for which context is not carefully controlled are notoriously variable.

iv. Over the last three decades, formal techniques like those used in semantics have been increasingly applied to pragmatics, to discourse, and to dialogue. Relatedly, there has been an ever greater awareness that semantic and pragmatic data are highly sensitive to context. So researchers are increasingly careful to contextualize examples, often presenting data in the form of mini-discourses rather than isolated single sentence examples.

v. There is a growing sensitivity to differences between speech and written language, ${ }^{1}$ and to the significance of prosody. Where

1 However, as yet little work in formal semantics and pragmatics references broader differences in genre, whereas this is standard in the related subfield of Conversation Analysis. Perhaps 
prosody is established to be significant, it is becoming common for data to be presented along with some form of prosodic transcription, e.g. ToBI (Silverman et al 1992).

vi. Semantics and Pragmatics are undoubtedly the areas of linguistics which most freely import new formal tools from mathematics, computer science, philosophical logic, and elsewhere. A recent example is the importation of Decision Theory and Game Theory from psychology and economics.

Advice to authors: We will encourage submissions based on primary data, especially from under-studied languages. Whatever the source of data and judgments, whether naturally occurring or constructed, whether from corpora, consultants or colleagues, we ask that authors are as specific as possible about that source. Information as to the source of data and judgments may be specified in footnotes by each example, in a single summary footnote near the beginning of the paper, or in the main text in case the source of the data is of particular relevance to the claims being made. We strongly encourage authors to consider making data publicly available, for example in the form of text or data files that can be hosted on the $S \& P$ site.

Many $S \& P$ articles will not make use of corpora or web data, but nowadays all authors must be aware that readers and reviewers have rapid access to corpus and web evidence. It would be as well for authors to forestall potential objections based on these sources by considering for themselves whether any such data might be relevant to their claims prior to submission.

\section{Open access}

Our field, like most of academia, has a long history of interdependence with big commercial publishers. The need to make a profit forces these publishers to limit circulation to those who can pay a hefty subscription, mostly libraries in large academic institutions in first world nations. But, the world has changed rather dramatically. What do commercial publishers do, and how can we manage to run a top rate journal without one?

Most obviously, publishers publish. But desktop publishing and typesetting software means we can generate high quality, stylish publications

work exploring the broader significance of genre will eventually appear in $S \& P$. 
A New Journal

ourselves. And the advent of print publication on demand means that even for good quality hard copy we do not need fixed subscriptions.

Publishers also distribute. But in the internet age, most of the distribution infrastructure we need has been paid for by others. At a low cost (which we can bear without charging readers) we can make everything we publish in our journal permanently accessible within minutes at any hour of any day to a billion or more people.

Publishers provide other services too. But the most important remaining components of a journal are already provided by the academic community for free. Authors, reviewers and editors all provide their services at no charge.

Thus it seems to us that a move to open access, electronically distributed non-commercial journals is inevitable. Overdue, even. Many fields have already begun to make the switch - you may be surprised at the huge range of journals (approaching 300o) listed in the Directory of Open Access Journals at doaj.org.

We should note that open access journals such as $S \& P$ are the second step in a hoped for open access revolution. The first step, which we urge all authors that publish their work in non-open-access journals to take, is to deposit "postprints" (the final manuscript version of an article after peer review and revisions) in open access archives and/or on the author's or their institution's website. This is commonly called "Green Open Access" and is within reach for virtually all of the output of our field, since even commercial publishers will grant authors the right to deposit the postprint on the web (some even do this routinely in their standard authors' agreement now, and some even allow the author to put the journal's final pdf version of the article on the web). If the standard author agreement does not include this right, we encourage authors to see whether they can amend the agreement to include that right; standard tools for adding such amendments are easily available on the web.

With journals like $S \& P$, this process of freely distributing the results of scientific research is made even smoother. Open access is a central part of the journal's mission. Advocates of open access call this "Gold Open Access". In fact, $S \& P$ is an example of what some call "Platinum Open Access", since we do not levy author charges. The rather minimal costs for the journal's operation are provided by institutional support (more on this in Section 10).

If you want more information on open access, the best source is Peter Suber's website: earlham.edu/ peters/fos/overview.htm. 
Beaver \& von Fintel

\section{Affiliation with the LSA's eLanguage Project}

As we mentioned, our journal will be published under the auspices of the Linguistic Society of America, under the umbrella of their new eLanguage initiative. eLanguage is an electronic publishing initiative which will include a set of new open access journals ${ }^{2}$ such as $S \& P$ as well as some additional resources (book notices, op-ed page, a grapevine news service about career movements in the field and major news about linguistic departments).

We see the affiliation of $S \& P$ with the LSA as a mutually beneficial relationship. The eLanguage team will coordinate the web hosting of the journal, including the infrastructure of the OJS open source journal management software. This will alleviate a lot of the headaches of running an electronic journal, which means that the editors can concentrate on getting top quality content into the journal. For the LSA, this provides a way of actively supporting and disseminating leading-edge research specific to the fields of semantics and pragmatics, something that, because of its generalist nature, has not been possible in the journal Language. We hope that as a result, the LSA will come to play a much more central role in our subfield than has been the case in recent years.

The LSA initially planned a restriction that eLanguage journal authors would have to be LSA members, as is the case for Language authors. But, after some negotiation, this requirement was dropped. As Puschmann \& Reimer (2007) from the eLanguage staff write in an article about the project: "Originally, the requirement that authors should be LSA members was included in the project outline, but this was dropped when it became increasingly clear that such a requirement would hamper the efforts of journals reliant on contributions from international scholars, many of whom were relatively unlikely to be LSA members. The choice for open access was thus also a completely practical one. Limiting access to eLanguage, even author access, would have affected quality and publication impact in a negative way, and this was a constraint that was deemed unacceptable both by journal editors and the society."

2 The LSA currently uses the term "co-journals" for the affiliated journals published under the eLanguage umbrella. We prefer the term "sister journal", since sisters are equals, but cowhen it combines with a noun can sometimes suggest a mere accompaniment. 
A New Journal

\section{Advisory Board and Editorial Board}

$S \& P$ will be guided by the advice of the following eminent scholars, who are the founding members of our Advisory Board:

- Gregory Carlson (former editor of Linguistics \& Philosophy)

- Gennaro Chierchia

- Bart Geurts (editor of Journal of Semantics)

- Irene Heim (editor of Natural Language Semantics)

- Laurence Horn

- Pauline Jacobson (editor of Linguistics \& Philosophy)

- Hans Kamp

- Angelika Kratzer (editor of Natural Language Semantics)

- Manfred Krifka (editor of Theoretical Linguistics, former editor of Linguistics \& Philosophy)

- William Ladusaw

- Barbara Partee

- Robert Stalnaker

The Editorial Board has more than one hundred experts in semantics, pragmatics, and adjacent fields on it (a full listing can be accessed at the journal's site, semprag.org). Our aim is to quickly have $S \& P$ associated with a strong reputation for high quality content. Having virtually the entire established research community literally "on board" is a significant step towards that aim.

\section{The author's side of the submission process}

Full author guidelines are available at the journal's site, but here is a summary of the submission process. For initial submission of an article, we do not require adherence to any particular style guidelines. We ask for a pdf of the article, with generous margins. The submission is made on the journal's website. There is an author's checklist that guides the authors 
through the steps involved in asking the journal to consider their article. All communication between the authors and the journal will be via the website and email. At any point during the process, we welcome personal messages to our joint editors' address: editors@semprag.org.

When an article is submitted to $S \& P$, we strongly encourage authors to also deposit their manuscript to the Semantics Archive (semanticsarchive.net) so as to allow the research community to read the pre-publication version and to give feedback on the work to the author. ${ }^{3}$ In the future, we will look into further ways of facilitating this kind of early feedback from the community.

When an article has been accepted after peer review and revisions, it is time to produce the final typeset version. The journal uses the $\mathrm{ETE}_{\mathrm{E}} \mathrm{X}-$ typesetting system and uses a specially designed set of style files. Highquality and fast publication is aided by extensive cooperation from the authors. Ideally, authors will provide a LTEX source file prepared to the guidelines of the journal. ${ }^{4}$ Authors who cannot do so must provide the journal's staff with a minimally marked up word processing file, which will then have to be converted to ETEX by the staff, which obviously will add to the processing time for an article. ${ }^{5}$ After proof-reading and any concomitant changes (which may require queries to be emailed to the author), a penultimate proof will be made electronically available to the author for checking. We hope that authors will be able to turn these around for us within a few days. After we make any final corrections that are needed, the article is ready. Two things then happen: first, the author is notified that the paper is being published, and second, the paper is published, spontaneously becoming available to something over a billion internet users.

\section{How peer review will work}

We anticipate submission and rejection rates comparable with the other top journals in our field. The editors will act as a first stage filter on papers, normally within a week of receipt. If a paper is determined to be of potential

3 Obviously, if an author chooses to submit an anonymous manuscript for blind peer review, as discussed in Section 7, they wouldn't want to choose to deposit the draft to the archive at the same time. But otherwise, we hold that it is the right thing to put the paper on the archive in parallel with the submission process.

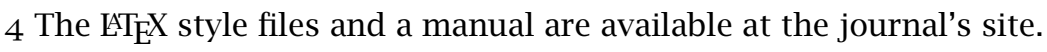

5 We would encourage authors who have not used LTEX to give it a try. There are user-friendly installations of the system available for all computing platforms. If you would like some advice on this, please contact us (editors@semprag.org). 
A New Journal

relevance, it will be sent to at least two reviewers drawn from our Editorial Board. The Editorial Board consists primarily of PhD holding academics active in the subfields of semantics and pragmatics, selected by the editors, and subject to advice from the Advisory Board. The Board will be of sufficient size that we will not normally call on the same reviewer more than twice in a year. The review board is public, but we will not reveal the identity of the reviewer of a particular paper except at the direct request of the reviewer.

We do not require that submitted papers be anonymous, since this is frequently an unattainable goal. However, the author of a paper has the right to remain anonymous to the reviewers throughout the review process. In that case, the author should take care to anonymize the paper, and should include in a clearly visible position on the front page the text "Submitted to $S \& P$ for anonymous review." The reviewers are then considered under obligation not to attempt to discern the identity of the author.

Following initial review, the editors will accept, reject, or call for revision. In case there is a need for revision, the editor may opt to request extended commentary from one or both reviewers in order to clarify what revisions are needed, and will then forward a request for revision to the author. Following revision, the editor may decide to publish, although following major revisions a paper will normally be sent for at least one further review. After acceptance, editorial assistants will take charge of proof-reading and formatting (see Section 8).

The editors will have based the review time on what they perceive to be the length and technical complexity of the paper, but will work on the assumption that writing a short review for a paper should normally require a half-day of work. Given that we aim to ask for at most two reviews per year from each reviewer, someone who accepts a position on our review board is making a commitment to approximately 1 day of work per year, or slightly more if we happen to ask for extended commentary, or a review of a particularly long or technically complex paper. This is by no means a trivial commitment, and we ask review board members to notify us immediately if it is beyond what they can offer. One of the most important goals of the journal is to keep time from submission to publication to a minimum. With the advantages of the open access format, and the strong commitment of our editorial board to this goal, we aim for a significantly faster time-to-publication than is currently common in linguistics. 
Beaver \& von Fintel

\section{What happens when we publish}

In accordance with the open access ethics of the journal, authors retain full copyright for their work. They grant a non-exclusive license to $S \& P$ to publish and archive their article. Readers can use the article under a Creative Commons Non-Commercial License, which gives them unrestricted rights to copy, distribute and transmit the work, provided the original author and source are credited. The default license also allows "derivative works", such as translations, without further authorization by the journal or the authors. Upon explicit request by the authors, any particular article can instead be published under a slightly more restrictive license which does not allow derivative works without specific permission by the authors. The copyright notice in the pdf of the article will specify which license the article is published under.

Once the final typeset version of an article has been produced by the journal's staff, it will immediately be published at the journal's website in pdf format. Thus, there is no delay at all, waiting for other articles to be bundled in an issue. This is unlike the "online first" publication of some of the commercial journals (where the online version has limited and provisional metadata, such as non-final page numbering).

The journal will start off by publishing one volume a year. There will not be separate issues bundling a subset of the articles in a volume. Instead, each article, so to speak, constitutes its own issue: the articles are numbered sequentially in the order they get published. For page numbering, we will adopt the scheme introduced by the ACM recently (Boisvert et al. 2007). The page numbering for each article will start at 1 . The page numbers in the article will indicate both the article number and the page number. So, the 17th page of the 3rd article in the first volume will have the page number 3:17.

\section{Visibility and preservation}

An important consideration for the choice of publication venue by academic authors is whether and how the publisher is committed to long term preservation and accessibility of the work. $S \& P$ has taken multiple steps on several fronts to give authors the peace of mind that their work is in good hands and will continue to be accessible for generations to come.

The journal is a member of CrossRef, a "not-for-profit network founded on publisher collaboration, with a mandate to make reference linking throughout 
A New Journal

online scholarly literature efficient and reliable." Its mission is to "serve as the complete citation linking backbone for all scholarly literature online, as a means of lowering barriers to content discovery and access for the researcher." ${ }^{6}$ What this means for $S \& P$ authors is that their article will be associated with a DOI (digital object identifier), which will serve as a permanent address for the article. CrossRef will maintain the integrity of the link and ensure that it will always point to the canonical version of the article, no matter what behind the scenes moves and changes in technology may occur. ${ }^{7}$ In addition, all reference lists at the end of $S \& P$ articles will list DOIs for any of the cited works that have one, so that readers can use those DOIs to access cited works in the most convenient way possible.

To further ensure maximal visibility and accessibility of work published in $S \& P$, the journal relies on the services of The University and State Library of Düsseldorf (“ULB”), which operates the database and web servers on which all of eLanguage is hosted. All articles will be indexed according to the thesaurus used by the leading German bibliography for linguistic studies, the Bibliography of Linguistic Literature Database ("BLLD”), a product of Frankfurt University Library. Thus, all papers will be included in the BLLD and other important linguistic bibliographies such as Linguistics Abstracts ("LABS") and the Bibliographie linguistique online ("BLO"). All work in $S \& P$ will also immediately be indexed on Google Scholar.

$S \& P$ has taken three separate steps to preserve the electronic content of the journal for the long term:

i. Since the journal is hosted in Germany, it falls under procedures for the persistent storage of scholarly content from digital sources such as e-journals and is thus preserved with the German National Library (Deutsche Nationalbibliothek).

ii. The hosting institution will harvest the meta data together with the full article content and ingest them in a Fedora repository (fedora-commons. org), which will serve as a long-term preservation back-up.

iii. Independently from the hosting in Germany, $S \& P$ will deposit every published article with Portico (portico.org), which is a publisher-

6 The quotes are from crossref.org/o2publishers/16fastfacts.html.

7 Thus, we encourage all authors to link to their article through its DOI rather than directly to its address on the $S \& P$ site. The DOI is also preferable to serving a separate copy of the article from the authors' own website, which would in addition lose potentially useful download statistics. 
funded service that provides a permanent archive of electronic scholarly journals. Portico was recommended to us by librarians we consulted on what kind of long-term preservation measures for electronic content were most trusted by academic libraries.

We are anticipating that there will be a yearly print volume containing all the articles published by $S \& P$ during the year. This will serve both as an additional back-up and as a way of providing the content of $S \& P$ to libraries and institutions that still wish to have hard copy. The print service will probably be provided by a commercial print-on-demand company. We plan to sell print volumes with a low mark-up which will serve to support the journal's operations.

\section{Financial structure}

As mentioned earlier, $S \& P$ is a "platinum open access" journal, which does not levy any kind of author charge. It is entirely free for authors and for readers. This is made possible by a support structure consisting of multiple institutions:

- Infrastructure and technical support provided by the Linguistic Society of America under its eLanguage initiative.

- Free and open source software available without cost, especially the OJS journal management software and the ${ }^{2} \mathrm{~T}_{\mathrm{E}} \mathrm{X}$ typesetting system.

- Start-up funding (and a small amount of continuing funds) provided by the MIT Library, the MIT Department of Linguistics and Philosophy, the MIT School of Humanities, Arts, and Social Sciences, and the University of Texas at Austin.

- The usual pro bono work of academics in writing, reviewing, and editing research articles.

The journal will need a small amount of continuing funds to support the staff work on typesetting the final manuscripts of accepted article. We are confident that these funds will be available to us in the future. Some revenue from the print volumes might also be available to support the journal's operations. So, we don't expect to ever have to levy author charges (although authors who are not able to submit $\mathrm{ET}_{\mathrm{E}} \mathrm{X}$-source might be encouraged some 
A New Journal

time in the future to support the staff's work on their manuscript by a voluntary donation).

\section{Transparency and community}

We very much hope that $S \& P$ will be representative of the semantics and pragmatics community, and that the community will feel involved in the project as it develops. We would like the day-to-day conduct of $S \& P$ to be as transparent as possible, and to that end we are publishing an editors blog at semantics-online.org/sp. We welcome comments, criticism, and questions at any time. Send us email at editors@semprag.org or comment on the blog.

\section{References}

Boisvert, Ronald F., Mary Jane Irwin \& Holly Rushmeier. 2007. Evolving the ACM journal distribution program. Communications of the ACM 50(9): 19-20. doi:10.1145/1284621.1284637.

Puschmann, Cornelius \& Peter Reimer. 2007. DiPP and eLanguage: Two cooperative models for open access. First Monday 12(10). URL http: //www.uic.edu/htbin/cgiwrap/bin/ojs/index.php/fm/article/view/1969. Silverman, Kim, Mary Beckman, John Pitrelli, Mari Ostendorf, Colin Wightman, Patti Price, Janet B. Pierrehumbert \& Julia Hirschberg. 1992. ToBI: A standard for labelling English prosody. In Proceedings of the International Conference on Spoken Language Processing (ICSLP), Vol. 2, 867-870. Banff.

David Beaver

Department of Linguistics

University of Texas at Austin

Calhoun Hall 501

1 University Station B5100

Austin

TX 78712-0198

editors@semprag.org
Kai von Fintel

Department of Linguistics \& Philosophy

Massachusetts Institute of Technology

Room 32-D808

77 Massachusetts Avenue

Cambridge

MA 02139-4307

editors@semprag.org 